\title{
MATERIALS RECOVERY FROM SHREDDER RESIDUES
}

E.J. Daniels, B.J. Jody, and J. Pomykala, Jr.

Argonne National Laboratory

9700 s. Cass Avenue

Argonne, IL 60561

B:OE

AUS 042000

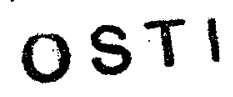

ABSTRACT

Each year, about five (5) million ton of shredder residues are landfilled in the United States. Similar quantities are landfilled in Europe and the Pacific Rim. Landfilling of these residues results in a cost to the existing recycling industry and also represents a loss of material resources that are otherwise recyclable. In this paper, we outline the resources recoverable from typical shredder residues and describe technology that we have developed to recover these resources. 


\section{DISCLAIMER}

This report was prepared as an account of work sponsored by an agency of the United States Government. Neither the United States Government nor any agency thereof, nor any of their employees, make any warranty, express or implied, or assumes any legal liability or responsibility for the accuracy, completeness, or usefulness of any information, apparatus, product, or process disclosed, or represents that its use would not infringe privately owned rights. Reference herein to any specific commercial product, process, or service by trade name, trademark, manufacturer, or otherwise does not necessarily constitute or imply its endorsement, recommendation, or favoring by the United States Government or any agency thereof. The views and opinions of authors expressed herein do not necessarily state or reflect those of the United States Government or any agency thereof. 


\section{DISCLAIMER}

Portions of this document may be illegible in electronic image products. Images are produced from the best available original document. 


\section{INTRODUCTION}

The most cost-effective process for recovering materials from obsolete consumer durables such as cars and appliances is to shred them and then recover the materials of value from the shred. This is clearly evident by the fact that this is the common business approach to processing obsolete durables today. Each year, more than 30 million obsolete cars are removed from service, and after useable or rebuildable parts are recovered by dismantling, most of these cars become feedstock for shredding operations. Obsolete cars represent the single largest source of scrap steel for steelmaking. Whereas ferrous and non-ferrous metals can be costeffectively recovered, the other materials from obsolete cars and appliances have not been profitably recovered to date. Consequently, about 15 million tons of waste, commonly referred to as auto shredder residue are landfilled each year throughout the world; about 5 million tons per year in North America, 5 million tons per year in Europe and 5 million tons per year in the Pacific Rim. Clearly, landfilling of this resource imposes a direct cost on existing shredding operations. Less obvious, however, is the opportunity cost that results from dumping the profitable materials resources that are contained within shredder residues.

In this paper, we outline an approach to maximize the profitable recovery of material resources from shredder residues based on extraction technology developed at Argonne National Laboratory.

\section{SHREDDER RESIDUE:OPPORTUNITY COSTS AND PRODUCT OPPORTUNITIES}

There are about 200 shredder operators in North America and more than 500 throughout the world. Each shredder processes a different mix of feed material of cars, appliances, and other prompt and obsolete metal scrap. Each shredder operates their process under slightly different conditions. For example, most use two stages of magnetic separation while others use only one. Some use eddy current separation for non-ferrous metals recovery, others use flotation systems and others do not recover non-ferrous materials on-site. Some shredders are operated dry while others spray the infeed material for dust control. Obviously, the composition of shredder residue varies from shredder to shredder and from day to day at each shredder depending on the mix of feed material.

Typically, we have found that shredder residue (dry basis) contains about $10 \%$ ferrous and non-ferrous metals, $10 \%$ polyurethane foam, $40 \%$ fines material (less than $1 / 4$ inch) that contains metal oxides, glass, dirt, sand and wood, and $40 \%$ other organics including fibers and mixed polymers. Although this composition may vary slightly (more so with regard to metals content), variations that we have observed do not significantly alter either the overall approach or ultimately the basic process design for recovering materials from shredder residue.

Over the years, any number of alternatives to landfilling have been proposed for dealing with shredder residue ranging from use of shredder residues as an energy source (e.g. incineration), use of shredder residues as feedstocks for production of fuels or chemicals (e.g. pyrolysis, gasification), and use of shredder residues as fillers in other bulk materials (e.g. plastic logs) $(1,2)$. While any of these options might be technically feasible, they ignore the inherent value of the materials contained within shredder residue and can, at best provide little more than an offset against the direct costs of landfilling shredder residues. For example, even in the case of converting shredder residues to fuels or chemicals, the maximum value of the 
shredder residues cannot exceed that of an alternative feedstock such as coal. In this case, the value of the shredder resides would be about $\$ 0.01$ per pound. Similarly, if shredder residues are used as fillers, there are many low-cost fillers that the residues must compete with.

On the other hand, if we consider the values of the individual materials contained within shredder residue, in particular the polymeric materials, some of which have values in excess of $\$ 0.25$ per pound, we can then see the potential in recovering the opportunity costs of these materials - if we can recover them in a quality sufficient to gain this market opportunity.

\section{SEPARATION/EXTRACTION TECHNOLOGY: PRODUCT RECOVERY}

Typically, we can expect about $75,000,000$ pounds of shredder residue to be generated as a result of processing about 100,000 auto hulks for metals recovery. The technical approach that we have taken to process shredder residues for materials recovery includes a first-stage bulk separation followed by second-stage processes for recovery and conditioning of product materials. The overall process-materials flow is outlined in Figure 1. Products which are targeted for recovery include: a clean polyurethane foam, conditioned iron-oxides, and selected high-volume polymers including polypropylene, polyethylene, EPDM, ABS, HIPS, nylons, PVC, and polyester TP. Ferrous and non-ferrous metals are recovered as by-products during the recovery of the targeted materials. The principal residual material remaining is a plastics concentrate that will include more than 20 different types of lower-volume automotive materials. At present, because of volume and value, these materials cannot be cost-effectively recovered as individual materials.

\section{Bulk Separation}

The first-stage bulk separation is accomplished using a specially designed two-stage trommel that yields three product fractions: fines, dirty polyurethane foam, and a plastics concentrate. The oxides fraction includes materials of less than $1 / 4 \mathrm{inch}$, the foam fraction contains large, light materials and is predominantly large chunks of flexible-urethane, automotive-seat foam and the plastics concentrate will contain the balance of the incoming shredder residue. Each of the three fractions is then conveyed to second-stage processing for materials recovery and conditioning. Magnetic head pulleys on conveyors facilitate the recovery of ferrous metals entrained in the fractions.

\section{Second-Stage Processing}

Second-stage processing is required to recover products that meet the needs of the market. Recovered products include clean polyurethane foam, an iron-oxides concentrate, and selected polymeric materials.

\section{Polyurethane Foam Processing}

Typically, the polyurethane foam materials recovered from shredder residue will be contained entrained oils, dirt and some metals. The foam pieces will also be of varying dimensions ranging from about 1 -inch pieces up to 8 -inch chunks. To produce a marketable foam product, the foam is first sized in a secondary shredder to produce consistently sized pieces about 1 inch $\times 1$ inch $\times 4$ inches. Shredding also facilitates the liberation of entrained metals and dirt. After shredding and screening, the foam is conveyed to a continuous-wash, rinse and dryer system, Figure 2, to produce clean foam for the rebond market. Heavy 
components such as rubber compounds and non-ferrous metais are recovered from the foam wash tank. The cleaned and dried foam is then baled for shipment, Figure 3. In general, one pound of clean foam is recovered from two pounds of dirty foam $(3,4)$.

\section{Oxides Processing}

The fines fraction from shredder residue is typically about 40 weight percent of the shredder residue. It will contain metal-oxides, dirt, glass, sand and residual amounts of organics including oils and small-particle-size polymeric material. Magnetic separation of this material followed by wet sink-float separation can produce a high-quality iron-oxide concentrate (greater than $60 \%$ iron, with low concentrations of alkali metals and residual organics) that can be used as an alternate iron unit for cement making. The iron-oxide concentrate is typically about $1 / 3$ of the weight of the fines fraction from shredder residue.

\section{Polymeric Materials Recovery}

The mixed-polymer concentrate from the bulk separation of shredder residue is further processed to recover selected polymers. The concentrate will include materials of varying particle sizes. Therefore, the first step in recovery of specific polymers from this mix is granulation, to produce a consistent particle size of about $1 / 4$ inch for subsequent separation. Separation and recovery of specific polymers is accomplished using a wet sink-float system that includes froth-flotation for separation of equivalent-density polymers from each other.

A two-stage sink-float system is used to produce three initial cuts: a light, a heavy and a middling fraction. The light fraction will contain light rubber compounds such as EPDM and polyolefins. The EPDM can be recovered from the polyolefins using sink-float and the polyolefins can be separated from each other using froth-flotation. The middling fraction will contain polymers such as ABS, ABS-PC alloys, SAN, PC and HIPS. The HIIPS can then be separated from this fraction using froth-flotation (5). The ABS, SAN, and PC materials are compatible and can be recycled without further processing. The heavy fraction will typically contain a PVC concentrate. Other high-volume/high-value materials such as nylons and polyester TP can be recovered using staged sink-float and froth-flotation. Recovery of these materials accounts for about $2 / 3$ of the mixed-polymer fraction produced by the bulk separation stage, leaving a mixed-plastics fraction containing about twenty different polymers. This residual fraction is predominantly thermosets that might have value as a fuel feedstock because the thermosets cannot be re-used directly.

\section{MARKET ISSUES}

Various aspects of the process that we have developed have been confirmed through large-scale-pilot demonstrations. These include recovery of a clean polyurethane foam, recovery of an iron-oxide concentrate, and recovery of a high-quality ABS product. Product testing has confirmed that these materials meet the requirements of the market, Figure 4 . The key to long-term viability in recovering materials from shredder residue, is the ability to recover materials of consistent quality day in and day out. 


\section{CONCLUSIONS}

A process for recovering materials from shredder residue has been developed. Key aspects of the process such as recovery of the polyurethane foam, recovery of iron-oxides, and recovery of a high-quality ABS have been demonstrated at the large-pilot scale. The balance of the process (i.e. polymer recovery) has been confirmed by bench-scale experiments. Although actual yields will vary depending on the materials fed into the shredding operation, recovery of these materials from shredder residue can result in revenues in excess of $\$ 150$ per ton of shredder residue.

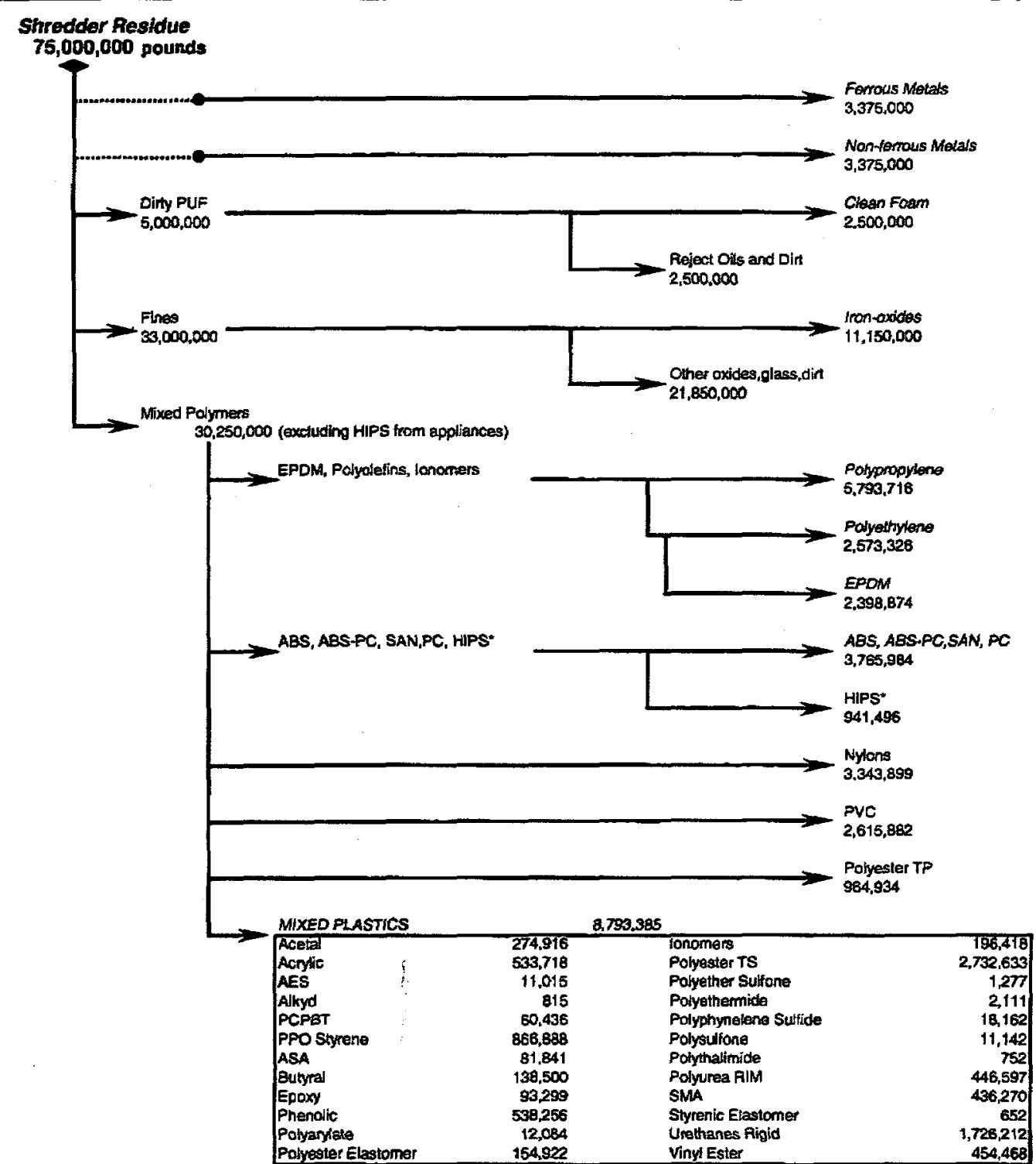

13 All units in pounds

2) 75 million pouncs of shredder residue is producad by shredding about 100,000 auto hulks.

3) Polymer composition is based on 1002 aulomotive use, excluding tires.

4) HiPS is based on stredding about 20 weight per cent appliances with the auto hulks. 


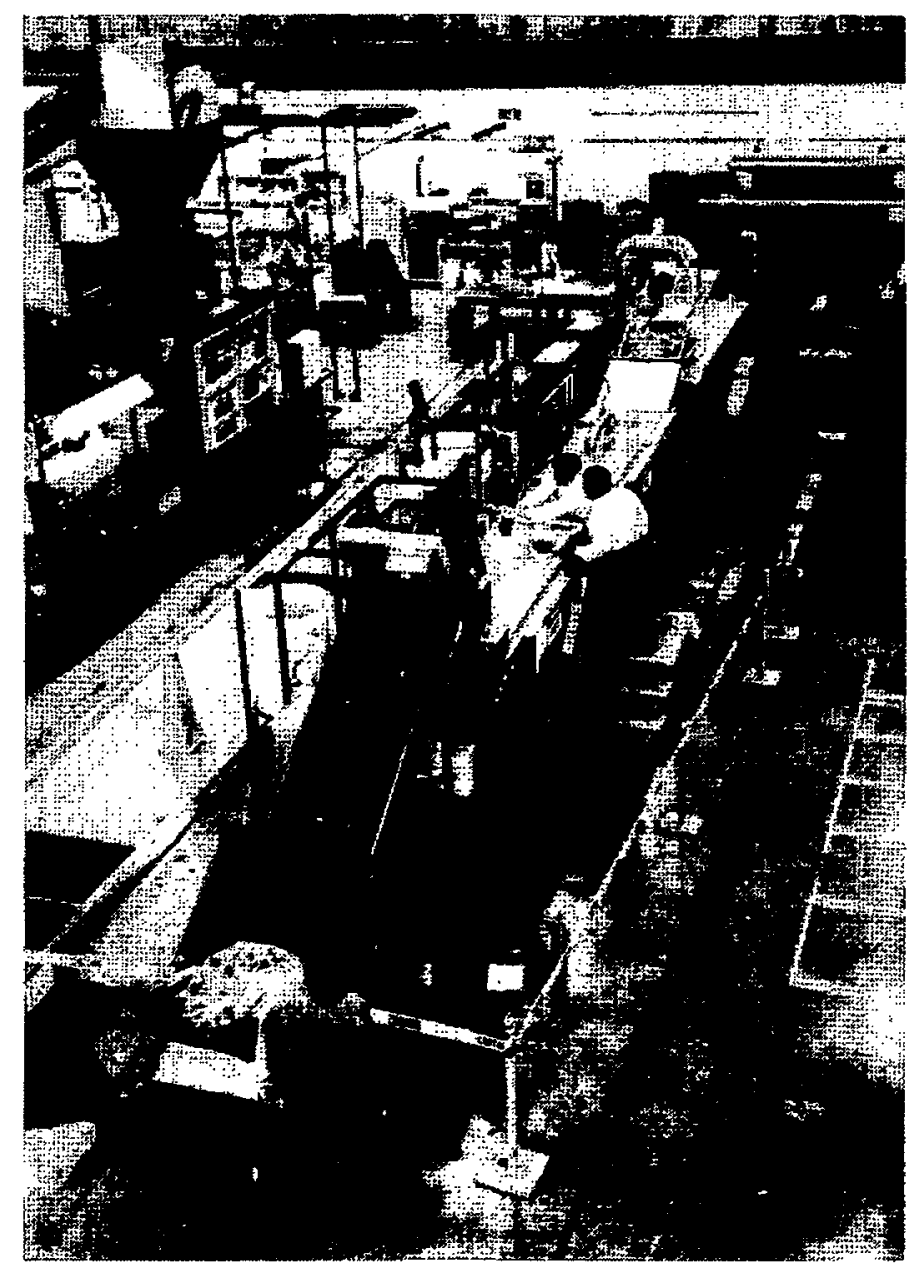

Figure 2- Argonne's Continuous-Polyurethane-Foam Wash, Rinse and Dry Process Equipment (3)

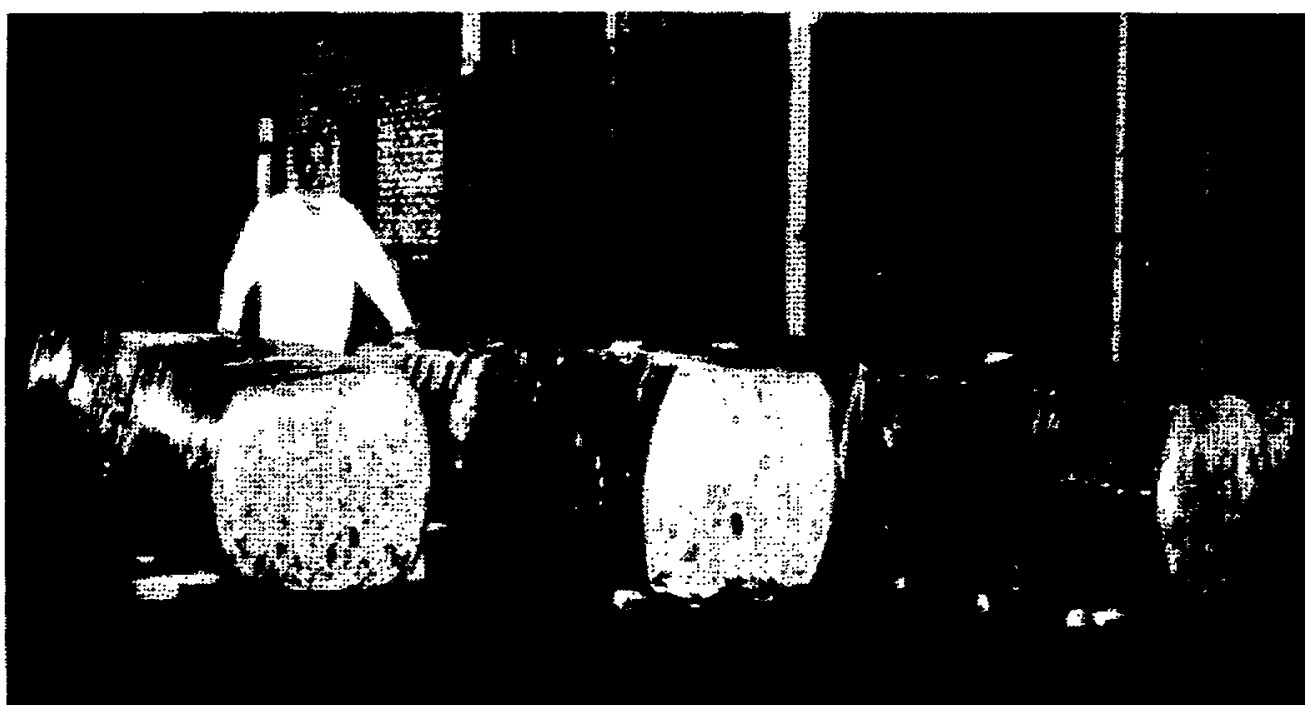

Figure 3- Cleaned Polyurethane Foam Bales Ready for Shipment 


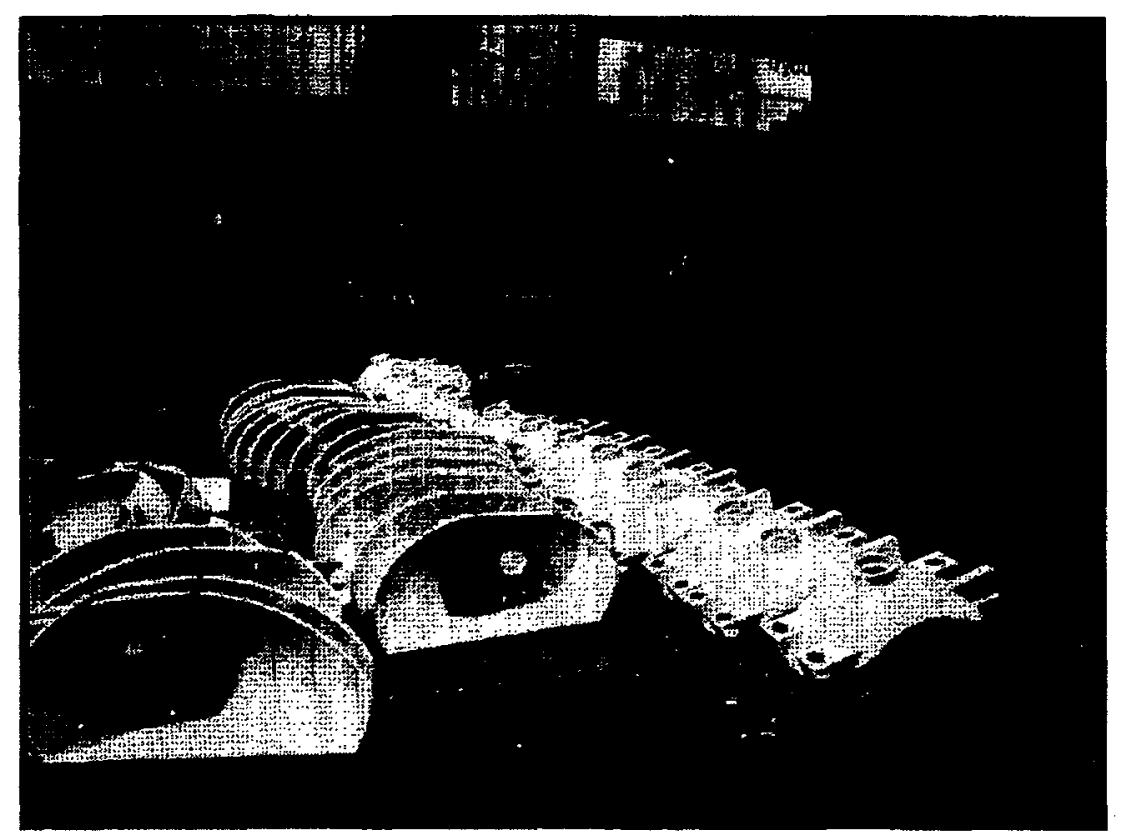

\section{Figure 4- Headlamp Backcans Produced from 100\% Post-consumer} ABS recovered from Appliance Shredder Residue

\section{ACKNOWLEDGEMENTS}

This work was sponsored by the U.S. Department of Energy, Assistant Secretary for Energy Efficiency and Renewable Energy, Office of Industrial technologies, under contract W-31-109Eng-38.

\section{REFERENCES}

1. Daniels, E.J., B.J. Jody, and P.V. Bonsignore, "Alternatives for Recycling Automobile Shredder Residue", The Journal of Resource Management and Technology, Vol.20, No.1, pp.14-26 (March, 1992).

2. Jody, B. J. and E. J. Daniels, "Automobile Shredder Residue: Treatment Options", Hazardous Waste \& Hazardous Materials, Vol.8, No.3, pp.219-230 (September, 1991).

3. Jody, B., E. Daniels and J. A. Libera, "Efficient Continuous Dryer for Flexible Polyurethane Foam and Cleaning Apparatus," U.S. Patent, No. 5,882,432, 16 March 1999.

4. Jody, B.J. and E.J. Daniels, "Recovery of Flexible Polyurethane Foam from Shredder Residue," Report ANL/ESD/TM-152, 1999, Argonne National Laboratory. 
5. Jody, B.J., B. Arman, D. Karvelas, J. Pomykala and E.J. Daniels, "Method for the Separation of High Impact Polystyrene (HIPS) and Acrylonitrile Butadiane Styrene (ABS) Plastics," U.S. Patent, No. 5,653,867, 5 August 1997. 